\title{
IMPROVED KARST SINKHOLE MAPPING IN KENTUCKY USING LIDAR TECHNIQUES: A PILOT STUDY IN FLOYDS FORK WATERSHED
}

\author{
Junfeng Zhu*, Timothy P. Taylor, James C. Currens, and Matthew M. Crawford \\ Kentucky Geological Survey, University of Kentucky, 504 Rose Street, 228 MMRB, Lexington, Kentucky 40506
}

\begin{abstract}
The existing sinkhole database for Kentucky is based on low-resolution topographic maps created more than fifty years ago. LiDAR (Light Detection and Ranging) is a relatively recent technique that rapidly and accurately measures features on earth's surface in high-resolution. To test the feasibility of using LiDAR to map sinkholes in Kentucky, we have developed a method of processing LiDAR data to identify sinkholes and tested the method in portions of the Floyds Fork watershed in central Kentucky. The method consisted of four steps, creating a high-resolution digital elevation model (DEM) from LiDAR data, extracting surface depression features from the DEM, inspecting the depression features for probable sinkholes, and verifying the probable sinkholes in the field. A total of 1,683 probable sinkholes were identified in the study area, compared to 383 previously mapped for the same area. We field-checked 121 randomly-selected probable sinkholes and confirmed that 106 of them were karst sinkholes. This method increased the number of sinkholes by a factor of four with a success rate between $80 \%$ and $93 \%$ for the study area, demonstrating that the LiDAR sinkhole-mapping method is reliable and efficient. This method identified approximately $55 \%$ of the previously mapped sinkholes, and approximately $98 \%$ of the missed sinkholes appeared to be filled or covered for urban development and agriculture purposes. The next step is to extend this method to provide high-resolution sinkhole maps for other karst areas in Kentucky where LiDAR data become available.
\end{abstract}

\section{INTRODUCTION}

Detailed mapping of sinkholes is critical in understanding hydrological processes and mitigating geological hazards in karst landscapes. Sinkholes are surface depressions that form in places where carbonate rocks are dissolved from water and overlying soil particles are carried away underground, causing the surface to subside gently or collapse suddenly (Ford and Williams, 1989; Currens, 2002; Brinkmann, 2013). There are three general types of sinkholes, dissolution sinkholes, coversubsidence sinkholes, and cover-collapse sinkholes (Tihansky, 1999). Sinkholes serve as a major connection between surface water and groundwater by collecting rainfall and draining it internally into the subsurface. Sinkholes can cause damage to private property and civil infrastructure such as buildings and roads. Covercollapse sinkholes, which occur when the material overlying subsurface voids collapses, can cause damage to buildings and roads, farm ponds, and farming equipment (Currens, 2002). Because of their fixed cross-section area, sinkholes are prone to overflow and flooding. Some sinkholes can act as springs and discharge water to the surface during intense storms (Currens, 2002). Dinger et al. (2007) estimated the damages associated with sinkholes in Kentucky were approximately \$23 million dollars per year. Consequently, existing land-use planning in karst areas often relies on detailed mapping of sinkholes (Fleury, 2009).

Some sinkholes can be recognized from the USGS 1:24,000 scale topographic maps. These topographic maps include closed depression features, often indicative of sinkholes in karst terrains. In the last few decades, several states have developed digital sinkhole databases based on the topographic maps (Beck, 1984; Florea et al., 2002; Paylor et al., 2003; Alexander et al., 2013). Developing a sinkhole database from topographic maps first requires digitization of the closed depressions, which is often labor intensive because the number of sinkholes is commonly in the thousands on a regional scale (Florea et al., 2002). In addition, the topographic maps have elevation contour intervals of $3 \mathrm{~m}, 6 \mathrm{~m}$, or higher, resulting in shallow and small sinkholes being overlooked. Furthermore, most USGS topographic maps were created prior to the 1970s, and many new sinkholes may have developed since then. Although people recognize that not all closed depressions illustrated in these topographic maps are sinkholes, extensive field verification of the depressions rarely occurs, because the process is slow and costly.

Remote-sensing data have long been recognized as useful in locating sinkholes (Newton, 1976). Highresolution, high-accuracy data obtained from modern

*Corresponding author: Junfeng.zhu@uky.edu

Journal of Cave and Karst Studies, December 2014 •207 
remote-sensing technology provide opportunities to improve sinkhole mapping. For example, Littlefield et al. (1984) applied Landsat images to study the relationship between lineaments and sinkholes in west-central Florida. Dinger et al. (2007) used a spectrum enhancement method on $1 \mathrm{~m}$ resolution natural-color images to extract circular shapes that represented areas with different vegetation signatures than surrounding areas. Some of the circular shapes were found in the field to be active sinkholes. In this study, we used LiDAR (Light Detection and Ranging) to improve sinkhole mapping. LiDAR is a remote-sensing technique that rapidly and accurately measures features on the earth's surface by sending out short laser-light pulses and measuring their returns from an aircraft or a terrestrial platform. A laser pulse can have one or multiple returns because the pulse can encounter multiple reflection surfaces when it travels toward the earth's surface. Collected LiDAR data, called point clouds, are often post-processed to classify the points into several categories, including ground, vegetation, building, and water. LiDAR excels in revealing small surface features and has been widely used in studying natural resources and the environment (Evans and Hudak, 2007; Floyd et al., 2011; Crawford, 2012). LiDAR has also been applied in studying sinkholes in some other states. Seale (2005) and Seale et al. (2008) used LiDAR, also called airborne laser swath mapping, to map sinkholes in Pinellas County, Florida. They suggested that contemporaneous aerial photographs should be used in conjunction with LiDAR for reliable sinkhole mapping. Rahimi et al. (2010) and Rahimi and Alexander (2013) applied LiDAR to verify sinkholes mapped in the 1980s and 1990s in Winona County, Minnesota. They found that most of the inventoried sinkholes that had not been filled later for agricultural uses were visible using LiDAR. Mukherjee and Zachos (2012) used a sink-filling method to identify sinkholes from LiDAR and found an excellent match between LiDAR-identified and actual sinkholes in Nixa, Missouri. To test the feasibility of LiDAR in providing accurate and detailed sinkhole information for Kentucky, we developed a sinkhole-mapping method based on LiDAR point clouds and applied the method in a small karst watershed in central Kentucky.

\section{Study Area}

The study area, Floyds Fork Watershed, is located approximately $16 \mathrm{~km}$ east of Louisville, Kentucky (Fig. 1). The watershed consists of two 10-digit USGS hydrologic units and drains parts of Bullitt, Henry, Jefferson, Oldham, Shelby, and Spencer counties, covering approximately $736 \mathrm{~km}^{2}$. The Floyds Fork stream originates in the southwestern portion of Henry County and flows southwest to the Salt River, which flows to the Ohio River. The area has a subtropical climate with average annual precipitation of $117 \mathrm{~cm}$ (National Drought Mitigation Center, 2013).
Most of the Floyds Fork watershed is in the Outer Bluegrass physiographic region, and a small southwest portion of the downstream watershed is in the Knobs region (Fig. 1) (Woods et al., 2002). The Outer Bluegrass region has low to moderate relief with variable soil depth ranging from thick over limestone to thin over shales (Newell, 2001). The region is underlain by limestones, dolomites, and shales of Late Ordovician and Silurian age. The major formations are, from oldest to youngest, the Grant Lake Limestone, the Bull Fork Formation, the Drake Formation, the Osgood Formation, the Laurel Dolomite, the Waldron Shale, and the Louisville Limestone. The Osgood Formation and the Waldron Shale are composed of mostly shale ( $90 \%$ or higher) and very little dolomite. The remaining units are carbonate rocks (i.e., limestone and dolomite) with small amounts of calcareous shale. Most karst development occurs in these formations. The Knobs region is dominated by rounded hills, ridges, and narrow, high-gradient valleys (Woods, et al, 2002). Most of the Knobs region is non-karst and is underlain by diverse shale, mudstone, and limestone sedimentary rocks of Silurian and Mississippian age.

\section{Data AND Method}

The data used in the sinkhole-mapping method included mainly LiDAR point clouds and aerial photography. The LiDAR data were provided by the Louisville/ Jefferson County Information Consortium (LOJIC) through the Kentucky Division of Geographic Information and cover Bullitt, Jefferson, and Oldham Counties. LiDAR data were collected in March 2009 with an average point spacing of $1 \mathrm{~m}$ and a vertical root-mean-square error of $8.8 \mathrm{~cm}$. The LiDAR points were post-processed into several categories. The categories associated with physical features include ground, low vegetation, medium vegetation, high vegetation, building, and water. The actual study area, which excluded non-karst areas, was approximately $580 \mathrm{~km}^{2}$, or $79 \%$ of the watershed (Fig. 1). Bing Maps was the primary aerial photography used for this study. Data from Bing Maps were imported directly into ArcMap 10.1 (ESRI, 2012) as base maps. In addition to Bing Maps, we also used Google Earth historic images and aerial photography collected by LOJIC at two different times, one in 2009 and the other in 2012.

The sinkhole-mapping method has four steps, building a digital elevation model (DEM) from LiDAR point clouds, extracting surficial depression features for the DEM, inspecting the depression features for probable sinkholes, and field-checking the probable sinkholes. The first three steps were carried out in ArcMap 10.1.

In the first step, the LiDAR ground points were used to create a DEM with a cell size of $1.5 \mathrm{~m}$ using an average binning method. The average binning method calculates the elevation for each cell by assigning the average value of all points in the cell. More sophisticated interpolation 


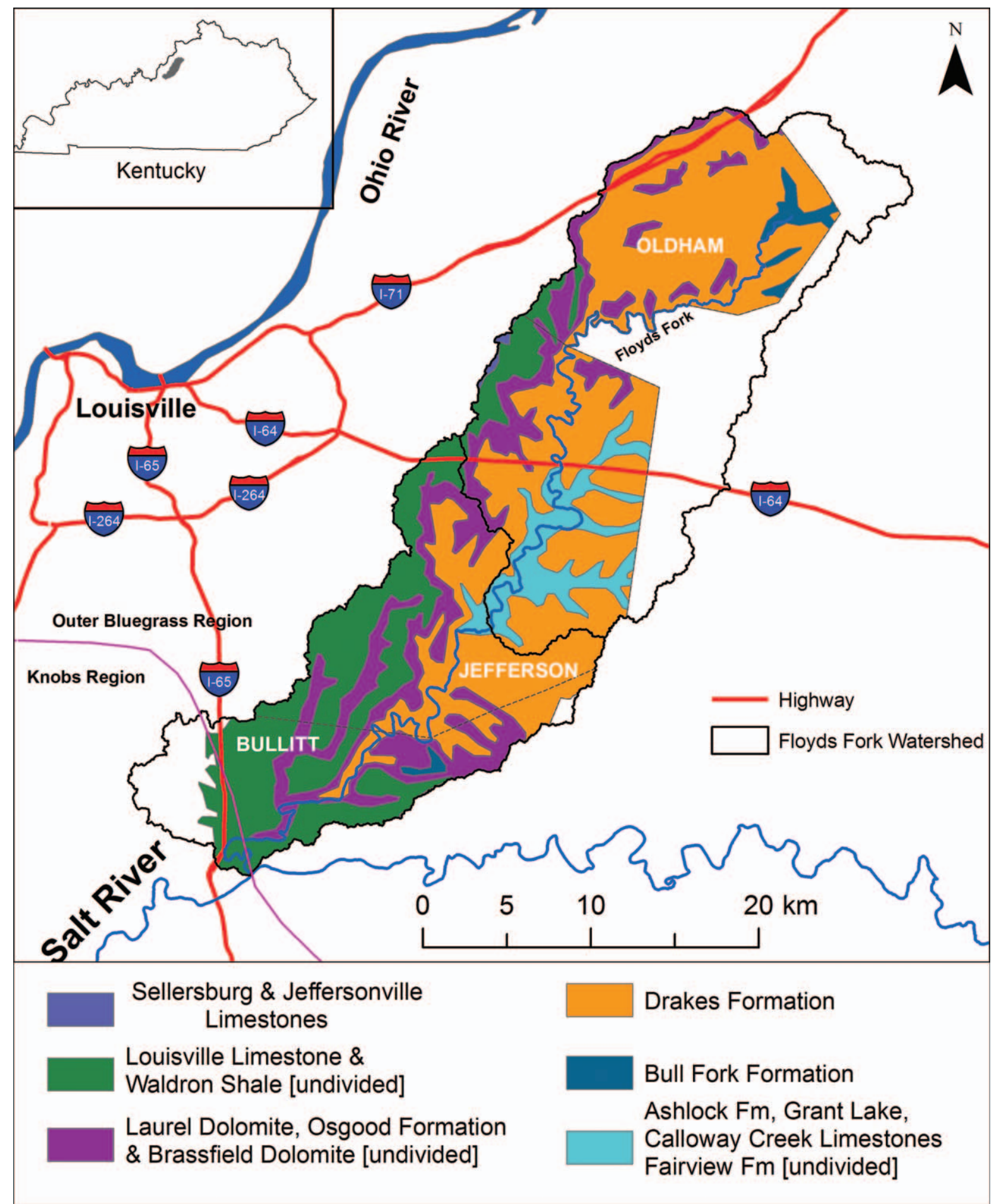

Figure 1. Location and geology of the study area. The Floyds Fork watershed is indicated by the irregular black line, with the bedrock geology shown for the karst portion that is the study area. The thin purple line is the boundary between the Blue Grass and Knobs regions.

methods, such as kriging, could potentially be used for this application. Because the cell size of the DEM was larger than the LiDAR point spacing, meaning at least one measurement is available for each cell, the average binning method was considered sufficient for this study.
Depression features were extracted from the DEM at the second step. A fill tool in ArcGIS was used to identify depression features on the DEM. The fill tool was originally developed to remove small depressions resulting from data noise; here it was used to find natural 
depressions. The tool fills depressions on the DEM with an optional user-specified maximum sink depth. All depressions that are less than the maximum depth and are lower than their lowest adjacent neighbor will be filled to the height of their pour points. We used a maximum depression depth of $6 \mathrm{~m}$, which allows identification of sinkholes that are less than $6 \mathrm{~m}$ deep. We considered this depth sufficient to identify most natural sinkholes in the study area. Mukherjee and Zachos (2012) found that a 4-m depth threshold was sufficient for identifying existing sinkholes in Nixa, Missouri. The fill tool generated a new filled DEM, and the depressions were then extracted by subtracting the filled DEM from the original DEM to create a depression raster.

The depressions identified in the fill procedure included depressions that were not sinkholes. Furthermore, we were interested in locating sinkholes that were considered to have a significant hydrologic impact in the Floyds Fork watershed, that is, sinkholes with relatively large drainage areas. For this reason, we selected the depressions with an area larger than $46 \mathrm{~m}^{2}$ and depth of greater than $0.3 \mathrm{~m}$ for further processing. The selected depressions were then converted from raster format to polygon format. These polygons were further smoothed, and the holes inside some polygons that were artifacts of the raster-to-polygon conversion process were removed. These procedures for generating depression polygons from LiDAR can be accomplished by sequentially using several ArcGIS commands, including LAS Dataset To Raster, Fill, Raster Calculator, Raster to Polygon, Smooth Polygon, and Eliminate Polygon Part. To streamline these procedures, we built a model tool with a single user interface. The model tool asks the user to provide a single input, the LiDAR dataset, and then executes the aforementioned commands with default parameter values (DEM cell size, fill depth, depression area, smooth tolerance, etc.) automatically to create depression polygons. The tool also allows a user to change the parameter values on the same user interface.

In the third step, every polygon was visually inspected and manually classified into one of three categories, probable sinkholes, suspicious sinkholes, and non-sinkholes. A shaded-relief map with $5 \times$ vertical exaggeration was created from the LiDAR DEM to amplify the shape and depth of the depression features. The shaded-relief map along with aerial photography was used to classify the polygons. Seale et al. (2008) and Alexander et al. (2013) also used aerial photography to help identify sinkholes in their studies. To ensure a consistent classification, the polygon classification was carried out by a procedure consisting of an initial classification, a review, and discussion. The initial classification and the review were conducted by different individuals. The review results were then discussed to reach the final classifications. Although many polygons needed to be inspected, many of them were unambiguously stream channels, water-filled ponds, swimming pools, and drainage structures and were very easily and quickly identified as non-sinkholes. On the other hand, natural sinkholes tend to have a circular or elliptical shape and many of them have one or more internal drainage points (i.e., throats) that are readily visible on the shaded-relief map. On occasions, the classification procedure could not lead us to a decision, and these ambiguous polygons were assigned to suspicious sinkholes.

In the fourth step, probable sinkholes were randomly sampled for field-checking. To create a random sample of probable sinkholes over the entire area, we first divided the area by creating a 3,000-by-4000 ft grid, producing a set of cells larger than the number of probable sinkholes, and then randomly selecting one sinkhole from each cell that contained at least one, creating a pool of probable sinkholes from which those to be field-checked were randomly selected. Field investigators used a GPS-enabled iPad with a map showing locations of the selected probable sinkhole. The iPad tracked locations of the field investigators in real-time in relation to the location of each target to minimize location errors; since sinkholes in the study area generally occur in clusters, it is easy to check the wrong location. To check a probable sinkhole in the field we considered whether the feature was a depression, whether drain holes existed inside the feature, whether man-made structure(s) existed within the feature, whether there was vegetation within the feature, and whether water existed within the feature. The same sampling and field-checking methods were also used for suspicious sinkholes.

\section{RESUlts AND Discussion}

We extracted approximately 10,720 depression polygons in the study area from the DEM created from the LiDAR dataset. Among the extracted polygons, 1,696 were classified as probable sinkholes and 282 as suspicious sinkholes. Approximately $10 \%$ of the probable sinkholes from Bullitt County and 5\% from Jefferson and Oldham Counties were selected for field-checking. Excluding the samples that were inaccessible, mostly due to absent landowners, we field-checked 121 probable sinkholes and confirmed 106 of them (88\%) as sinkholes (Fig. 2). We also randomly selected and field-checked 18 suspicious sinkholes and found 5 of them were actual sinkholes. The total number of actual sinkholes detected in the LiDAR data would be, based on the field-checking statistics, 1563 . The LiDAR-derived sinkhole coverage is available to the public on the Kentucky Geological Survey's online map service (http://kgs.uky.edu/kgsmap/kgsgeoserver/viewer.asp).

The large number of polygons generated indicated that the depression-extraction procedure was effective in locating surface depressions. Although some of the polygons were associated with sinkholes, more than $80 \%$ of them were stream channels, ponds, or road drains or other man-made structures. The number of sinkhole-like depressions can be reduced by using an automated 


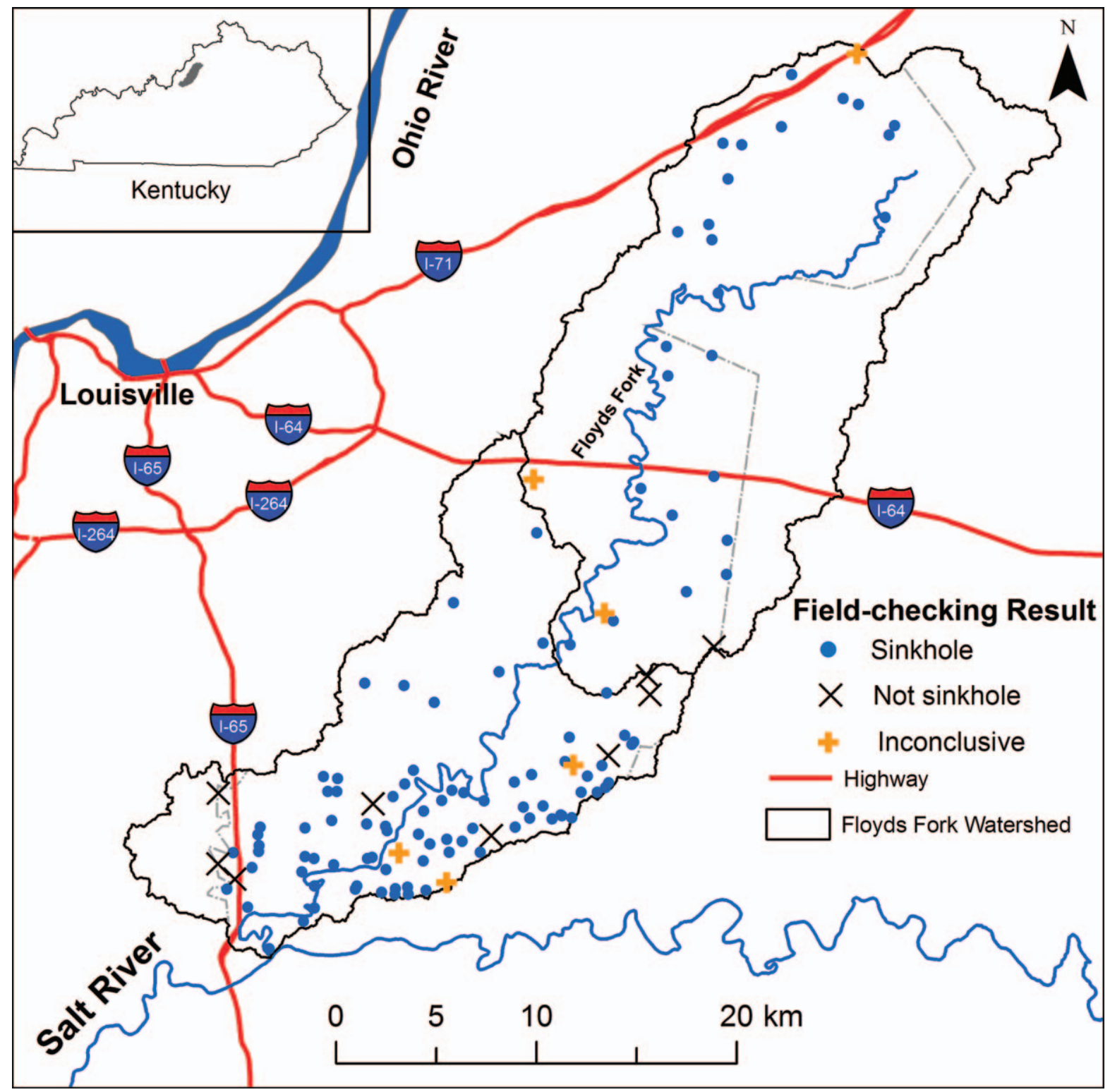

Figure 2. Field-checking results for randomly sampled probable sinkholes identified from the LiDAR data.

procedure. For example, Miao et al. (2013) illustrated one such procedure by using a random forest algorithm that uses shape and depth parameters to extract circular- or elliptical-shaped sinkholes from depressions. In our study area, we found that although most sinkholes have a circular or elliptical shapes, some sinkholes have more complicated shapes and may potentially be excluded by an automated procedure.

The polygon-classification process was actually quite fast and effective, because many polygons were easy to identify when using shaded-relief maps and high-resolution aerial photography (Fig. 4). Polygons associated with stream channels were the easiest to identify as nonsinkholes. On aerial photography, each had an elongated shape and overlapped stream channels; on a shaped-relief map, each had a smooth and flat bottom. The smoothed bottoms were artifacts on the DEM resulting from LiDAR beams being absorbed at the water surface. Polygons associated with water-filled ponds were also easily identifiable as non-sinkholes, because these polygons also had flat bottoms on shaded-relief maps. Polygons associated with man-made structures that have unnatural and irregular shapes were easily identifiable as non-sinkholes from aerial photography. On the other hand, some polygons associated with cover-collapse sinkholes were readily identifiable. On a shaded-relief map, those polygons had an internal drain that showed as a hole or throat inside the depression. Such polygons, when shown by aerial photography to be in a forested area of cluster of trees surrounded by grassland, were likely to be true cover-

Journal of Cave and Karst Studies, December 2014 •211 


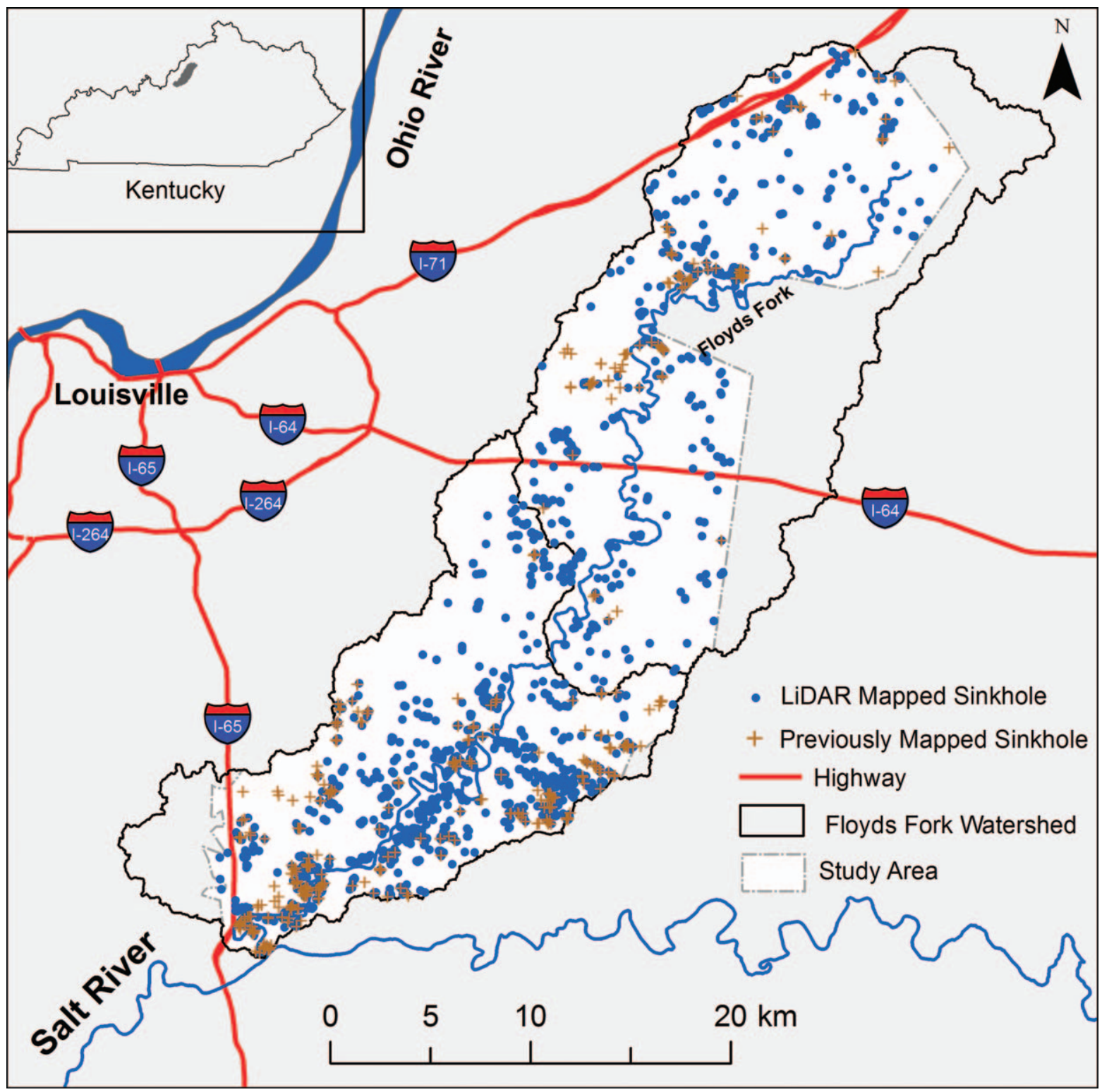

Figure 3. Comparison between sinkholes mapped from the LiDAR data and those previously mapped from topographic maps.

collapse sinkholes, but if those polygons were close to residential houses or roads, they could be either sinkholes or man-made retention basins with drains that appeared as holes. Polygons associated with subsidence sinkholes were harder to screen. On a shaded-relief map, they appeared as shallow, bowl-shaped depressions; on aerial photography, they could be in the middle of a farm field or close to a residential area. These polygons could have been either sinkholes or ponds that were empty when LiDAR was flown. For these polygons, we used historical aerial images to determine if these features were natural sinkholes or man-made ponds.

The field-checking of probable sinkholes showed an $88 \%$ success rate. However, the field-checked sinkholes were approximately $7 \%$ of all the sinkholes we identified.
To understand the overall success rate and the margin of error for the study area, we considered this problem as a binomial distribution with two possible outcomes, sinkhole and non-sinkhole, and used sample statistics to estimate population parameters. The estimated proportion, i.e., the success rate $(p)$ and standard deviation $\left(\sigma_{s}\right)$ are (Zar, 1999):

$$
p=\frac{X}{n} \quad \text { and } \quad \sigma_{s}=\sqrt{\frac{p(1-p)}{n-1}\left(1-\frac{n}{N}\right)},
$$

where $N$ is size of the population, $n$ is the number of samples, and $X$ is the number of success in the samples. We identified 1,696 probable sinkholes from LiDAR and fieldchecked 121. Among the 121 field-checked sinkholes, there are 106 sinkholes, 9 non-sinkholes, and 6 inconclusive. Considering all the inconclusive as non-sinkholes, the 

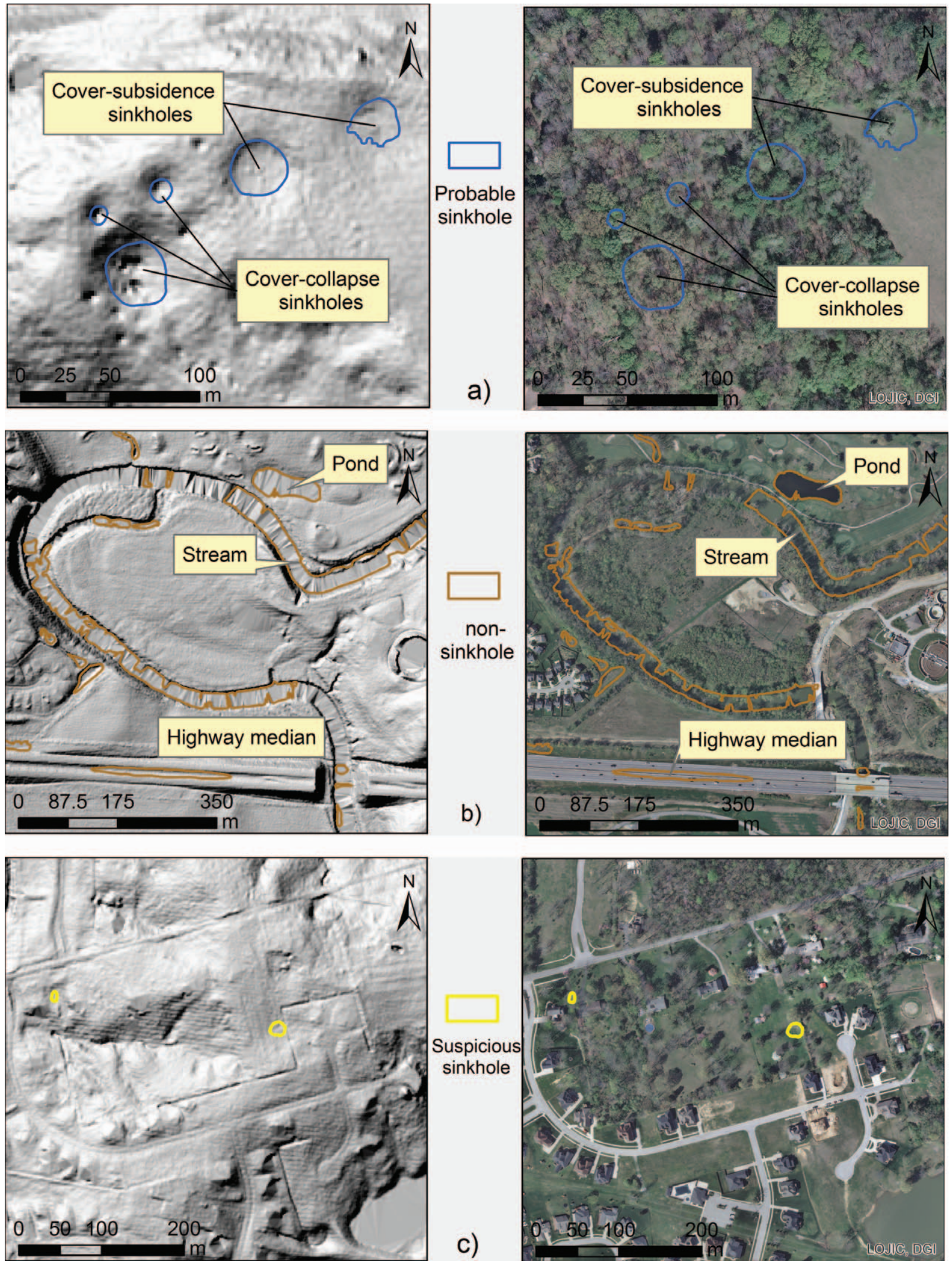

Figure 4. Examples of polygon classification, showing polygons overlain with shaded-relief (left) or aerial images (right): a) Examples of probable sinkholes. b) Examples of non-sinkholes. c) Examples of suspected sinkholes. The shaded-relief maps are $5 \times$ vertically exaggerated. 
Table 1. Summary of field-checking of probable sinkholes, showing three types of depression characteristics and their success rates.

\begin{tabular}{cccc}
\hline $\begin{array}{c}\text { Depression } \\
\text { Characteristics }\end{array}$ & $\begin{array}{c}\text { Number of } \\
\text { Field-Checked }\end{array}$ & $\begin{array}{c}\text { Number of } \\
\text { True Sinkholes }\end{array}$ & Success Rate \\
\hline With-berm-no-hole & 16 & 7 & $44 \%$ \\
No-berm-no-hole & 34 & 30 & $88 \%$ \\
& & & \\
No-berm-with-hole & 71 & 69 & \\
\end{tabular}

estimated success rate and standard deviation are 0.88 and 0.03 , respectively.

To estimate the margin of error, we calculated $95 \%$ of confidence interval based on Zar (1999), which calculates the lower confidence interval using

$$
L_{1}=\frac{X}{X+(n-X+1) F_{0.05(2), v_{1}, v_{2}}},
$$

where $v_{1}=2(n-X+1), v_{2}=2 X$, and $F_{0.05(2), v_{1}, v_{2}}$ is the 2tailed 0.05 critical value for a $F$ distribution with degrees of freedom $v_{2}$ and $v_{1}$; and the upper confidence limit using

$$
L_{2}=\frac{(X+1) F_{0.05(2) v_{1}^{\prime}, v_{2}^{\prime}}}{n-X+(X+1) F_{0.05(2) v_{1}^{\prime}, v_{2}^{\prime}}},
$$

where $v_{1}^{\prime}=v_{2}+2, v_{2}^{\prime}=v_{1}-2$, and $F_{0.05(2), v_{1}^{\prime}, v_{2}^{\prime}}$ is the 2-tailed 0.05 critical value for a $F$ distribution with degrees of freedom $v_{2}$ and $v_{1}$. Using equations (2) and (3), the lower and upper confidence limits are 0.80 and 0.93 . In another words, we have $95 \%$ confidence in stating that the success rate of the method for the study area falls between $80 \%$ and $93 \%$.

The success rate between $80 \%$ and $93 \%$ for the study area suggested that this method is reliable and promising. To further improve the reliability of the method, we explored the relationship between the field-checked depressions and true sinkholes by examined two prominent depression features, berms and holes, both of which were prominent on the shaded-relief maps. A berm is a prominent ridge along the rim of a depression, and a hole is a spot at the bottom of the depression that appears much deeper than its surroundings. All of the field-checked depressions fit into one of three categories: with-berm-nohole, no-berm-no-hole, and no-berm-with-hole. The number of field-checked depressions in each category and the success rate for each category are summarized in Table 1 . The no-berm-with-hole category made up 59\% of the overall field-checked depressions, and this category had the highest success rate $(97 \%)$ among the three categories. Most of the no-berm-with-hole features were revealed in the field as cover-collapse sinkholes, with the remainder being sinkholes with vertical rock openings or coversubsidence sinkholes. The no-berm-no-hole category made up $28 \%$ of the overall field-checked depressions. This category proved $88 \%$ successful, and most sinkholes in this category were cover-subsidence sinkholes. The with-bermno-hole category made up $13 \%$ of the overall checked sinkholes and had the lowest success rate (44\%). The bermlike shape proved to be a man-made structure for a waterholding pond. But through time, as residual insoluble fill in rock joints is eroded into underlying conduits, many ponds started to leak and eventually were unable to hold water, thus functioning as sinkholes. For this type of depression it was difficult to distinguish between a pond that holds water periodically and a pond-turned-sinkhole.

Among the fifteen probable sinkholes that were not confirmed as true sinkholes in the field, nine of them were confirmed as non-sinkholes; they were either stream meander cutoffs, ponds with water or trash, or man-made drains. The other five features, shown as inconclusive in 


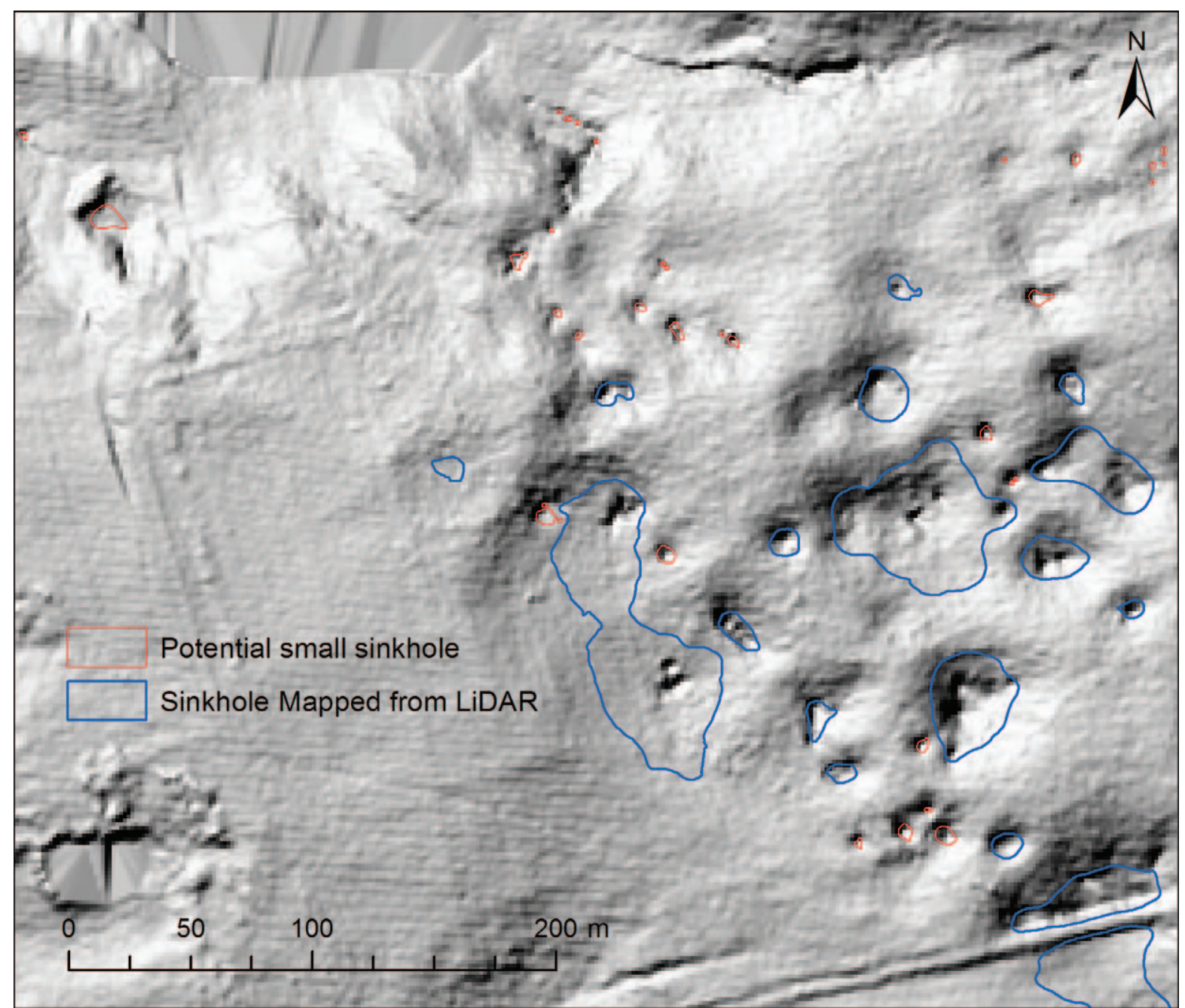

Figure 5. Shaded-relief map (5× vertically exaggerated) showing examples of potential small sinkholes not processed in this study.

Figure 2, could not be determined in the field. They appeared as a mix of natural karst features disturbed by human activities.

Since we focused on depression features that were $46 \mathrm{~m}^{2}$ and larger, smaller potential sinkholes were not included. From the shaded-relief maps, we noticed that in some areas where large sinkholes were present there were also smaller depression features that appeared to be sinkholes. Figure 5 shows an example of such areas. The method we developed can be readily tailored to identify the smaller sinkholes when resources become available.

The existing Kentucky sinkhole coverage, which was derived from the USGS topographic maps, had 383 sinkholes for the same area (Fig. 3). Among the 383 sinkholes, $215(56 \%)$ of them were also detected from the LiDAR data, and 168 (44\%) of them were missed. Sixteen of the sinkholes found in both databases had slightly different locations but obviously corresponded to the same features, judging from the shaded-relief map. A visual inspection of the sinkholes missed by the LiDAR analysis using recent aerial images showed that approximately half of them overlapped with man-made structures, such as roads, buildings, parking lots, and quarries, and the rest were located on open fields, such as pasture, but had either no or a very shallow depression associated with them. We speculate that many of those sinkholes may have been filled for agriculture or other purposes. This comparison showed that any sinkhole coverage needs to be updated frequently, because sinkholes are temporary features and can be easily enhanced, destroyed, or altered by human activities.

\section{CONCLUSIONS}

In this study, we developed a sinkhole-mapping method that uses high-resolution LiDAR and aerial photography to map karst sinkholes in detail. We applied the method to parts of the Floyds Fork watershed in central Kentucky and revealed four times as many sinkholes as the existing database for the same area. Field-checking suggested that the success rate of this method was between $80 \%$ and $93 \%$ 
for the study area, indicating the method is accurate and reliable.

High-density and high-accuracy LiDAR data provide a great opportunity for mapping karst sinkholes in high resolution and with great detail. In particular, bare-earth elevation data in LiDAR point clouds revealed sinkholes in forested areas that were undetectable using only aerial images. The depression-extraction procedure was effective in locating surface depressions, but it did not distinguish sinkholes from other depressions, resulting in the need for additional visual screening. Shaded-relief maps, especially with vertical exaggeration, revealed depression features in great detail and served as the primary tool for the visual screening process. Examining aerial images from different sources and time periods was also critical to distinguishing sinkholes from other depression features. Shape and depth characteristics of the depressions were closely related to the physical features they represented. Most non-sinkhole depressions can be easily identified. Furthermore, fieldchecking suggested that no-berm-with-hole depressions were most likely to be sinkholes and the with-berm-nohole depressions could be either sinkholes or ponds.

\section{ACKNOWLEDGEMENTS}

This study was supported by the Kentucky Geological Survey, and we would like to thank the Louisville/Jefferson County Information Consortium and the Kentucky Division of Geographic Information for providing the LiDAR data. Thanks also go to Liz Adams, Caleb Essex, Bailee Hodelka, Chase Lockhart, Mike Lynch, Brittany Shelton, Richard Smath, and Patrick Whalen, who assisted in the field-checking. We also thank three anonymous reviewers for their constructive comments, which greatly improved the manuscript.

\section{REFERENCES}

Alexander, S.C., Larson, E., Bomberger, C., Greenwaldt, B., Alexander, E.C., Jr., and Rahimi, M., 2013, Combining LiDAR, aerial photography, and Pictometry ${ }^{\circledR}$ tools for karst features database management, in Land, L., Doctor, D.H., and Stephenson, J.B., eds., Proceedings of the Thirteenth Multidisciplinary Conference on Sinkholes and the Engineering and Environmental Impacts of Karst: Carlsbad, National Cave and Karst Research Institute, Symposium 2, p. $441-448$.

Beck, B.F., 1984, A Computer-Based Inventory of Recorded Recent Sinkholes in Florida: Orlando, Sinkhole Research Institute, University of Central Florida, Rept. No. 84-85-1, 12 p.

Brinkmann, R., 2013, Florida Sinkholes, Science and Policy: Gainesville, University Press of Florida, $256 \mathrm{p}$.

Crawford, M.M., 2012, Using LiDAR to Map Landslides in Kenton and Campbell Counties, Kentucky: Kentucky Geological Survey, ser. 12, Report of Investigations 24, 12 p.

Currens, J.C., 2002, Kentucky is Karst Country! What You Should Know about Sinkholes and Springs: Kentucky Geological Survey, Information Circular 4, Series XII, 35 p.

Dinger, J.S., Zourarakis, D.P., and Currens, J.C., 2007, Spectral enhancement and automated extraction of potential sinkhole features from NAIP imagery - initial investigations: Journal of Environmental Informatics, v. 10, no. 1, p. 22-29. doi:10.3808/jei.200700096.
ESRI, 2012, ArcGIS Desktop: Release 10.1 SP1: Redlands, California, Environmental Systems Research Institute.

Evans, J.S., and Hudak, A.T., 2007, A multiscale curvature algorithm for classifying discrete return LiDAR in forested environments: IEEE Transactions On Geoscience and Remote Sensing, v. 45, no. 4, p. 1029-1038. doi:10.1109/TGRS.2006.890412.

Florea, L.J., Paylor, R.L., Simpson, L., and Gulley, J., 2002, Karst GIS advances in Kentucky: Journal of Cave and Karst Studies, v. 64, p. 58-62.

Floyd, C.T., Syverson, K.M., and Hupy, C.M., 2011, Using LiDAR data and ArcGIS to evaluate subtle glacial landforms associated with the Early Chippewa and Emerald Phase Ice-Margin positions, Barron County, Wisconsin [abs.]: Institute on Lake Superior Geology Proceedings, 57th Annual Meeting, Ashland, WI, v. 57, p. 35-36.

Fleury, S., 2009, Land Use Policy and Practice on Karst Terrains: Living on Limestone: New York, Springer, 187 p. doi:10.1007/978-1-40209670-9,

Ford, D.C., Williams, P., 1989, Karst Geomorphology and Hydrology: London, Unwin-Hyman, $601 \mathrm{p}$.

Littlefield, J.R., Culbreth, M.A., Upchurch, S.B., and Stewart, M.T., 1984, Relationship of modern sinkhole development to large-scale photolinear features, in Beck, B.F., ed., Sinkholes: Their Geology, Engineering \& Environmental Impact: Rotterdam, A. A. Balkema, p. 189-195.

Miao, Xin, Qiu, Xiaomin, Wu, Shuo-Sheng, Luo, Jun, Gouzie, D.R., and Xie, Hongjie, 2013, Developing efficient procedures for automated sinkhole extraction from lidar DEMs: Photogrammetric Engineering \& Remote Sensing, v. 79, no. 6, p. 545-554. doi:10.14358/PERS.79.6.545.

Mukherjee, A., and Zachos, L.G., 2012, GIS analysis of sinkhole distribution in Nixa, Missouri [abs.]: Geological Society of America Abstracts with Programs, v. 44, no. 7, 549 p.

National Drought Mitigation Center, 2013, Annual Climatology: Louisville, KY (SDF), http://drought.unl.edu/archive/climographs/LouisvilleANC. htm, accessed October 24, 2013.

Newell, W.L., 2001, Physiography, in McDowell, R.C., ed., The Geology of Kentucky - A Text to Accompany the Geologic Map of Kentucky: U.S. Geological Survey Professional Paper 1151-H, p. $79-83$.

Newton, J.G., 1976, Early Detection and Correction of Sinkhole Problems in Alabama, with a Preliminary Evaluation of Remote Sensing Applications: Alabama Highway Department, Bureau of Research and Development, Research Report no. HPR-76, 83 p.

Paylor, R.L., Florea, L.J., Caudill, M.J., and Currens, J.C., 2003, A GIS Coverage of Sinkholes in the Karst Areas of Kentucky: Kentucky Geological Survey, metadata file and shapefiles of highest elevation closed contours, 1 CDROM, (http://kgs.uky.edu/kgsweb/download/ karst/ksinks.zip).

Rahimi, M., Alexander, S.C., and Alexander, E.C., Jr., 2010, LiDAR mapping of sinkholes: Winona County, MN [abs.], Geological Society of America Abstracts with Programs, Joint Meeting North-Central/ South-Central Sections, v. 42, no. 2, p. 107-108.

Rahimi, M., and Alexander, E.C., Jr., 2013, Locating sinkholes in LiDAR coverage of a glacio-fluvial karst, Winona County, MN, in Land, L., Doctor, D.H., and Stephenson, J.B., eds., Proceedings of the Thirteenth Multidisciplinary Conference on Sinkholes and the Engineering and Environmental Impacts of Karst: Carlsbad, National Cave and Karst Research Institute, Symposium 2, p. 469-480.

Seale, L.D., 2005, Creation, analysis, and evaluation of remote sensing sinkhole databases for Pinellas County, Florida [M.S. Thesis]: Tampa, University of South Florida, $55 \mathrm{p}$.

Seale, L.D., Florea, L.J., Brinkmann, R., and Vacher, H.L., 2008, Using ALSM to identify closed depressions in the urbanized, covered karst of Pinellas County, Florida-1, methodological considerations: Environmental Geology, v. 54, p. 995-1005. doi:10.1007/s00254-0070890-8.

Tihansky, A.B., 1999, Sinkholes, west-central Florida, in Galloway, D., Jones, D.R., and Ingebritsen, S.E., eds., Land Subsidence in the United States: U.S. Geological Survey Circular 1182, p. 121-140.

Woods, A.J., Omernik, J.M., Martin, W.H., Pond, G.J., Andrews, W.M., Call, S.M., Comstock, J.A., and Taylor, D.D., 2002, Ecoregions of Kentucky (color poster with map, descriptive text, summary tables, and photographs): Reston, VA., U.S. Geological Survey (map scale $1: 1,000,000)$.

Zar, J.H., 1999, Biostatistical Analysis, 4th ed.: Upper Saddle River, NJ: Prentice Hall, 929 p. 